\title{
What the Human Genome Project hasn't told us: The epigenetics of development of esophageal squamous cell cancer
}

\author{
Victor A. Ferraris, MD, PhD
}

See related article on pages $378-85$.

Development of the Human Genome Project (HGP) holds great promise for identifying causes and treatments of human disease. This promise is mostly unfulfilled but is spiced with the development of remarkable, almost astounding, new knowledge. The course from inception of the HGP to today was "rocky" at best and sadly dysfunctional at worst. Beginning in May of 1985 starting with a workshop to discuss sequencing the human genome held in Santa Fe, New Mexico, until the HGP was declared complete in April 2003, there were private enterprise, government involvement, and pseudo-government initiatives that contributed to ultimate public availability of the human genome. Today, the sequence of the DNA in the human genome is stored in databases available to anyone with access to the Internet. How the genome came to be publically available amounts to a "swashbuckling" clash that ultimately led to the first publication of the draft of the human genome by a publically funded entity, the University of California Santa Cruz, in 2000. Today, the ultimate price tag of the HGP is approximately $\$ 3$ billion with more to come. So far, the return on this investment is modest. In fact, the more we learn about the human genome, the more levels of complexity become apparent. The article by Hsu and colleagues in this issue of the Journal is an example of this complexity. ${ }^{1}$

The realization that cancer progression required the participation of cellular genes provided one of several key rationales for embarking on the HGP in 1985. Cancer is ultimately a disease of unregulated gene expression. The reference human genome provided a building block for understanding the full spectrum of somatic changes leading to cancer. With increased understanding of the human genome and the transcription of genetic information, realization of the importance of epigenetic alterations in the transcription process surfaced. More specifically, study of cancer epigenetics identified epigenetic modifications to the genome of

\footnotetext{
From the Department of Surgery, Chandler School of Medicine, University of Kentucky, Lexington, Ky.

Disclosures: Author has nothing to disclose with regard to commercial support.

Received for publication Sept 16, 2014; revisions received Oct 6, 2014; accepted for publication Oct 11, 2014

Address for reprints: Victor A. Ferraris, MD, PhD, Department of Surgery, Chandler School of Medicine, University of Kentucky, A301, Kentucky Clinic, 740 South Limestone, Lexington, KY 40536 (E-mail: ferraris@uky.edu)

J Thorac Cardiovasc Surg 2015;149:386-7

$0022-5223 / \$ 36.00$

Copyright (c) 2015 by The American Association for Thoracic Surgery

http://dx.doi.org/10.1016/j.jtcvs.2014.10.070
}

cancer cells that do not involve a change in the nucleotide sequence. Epigenetic alterations are as important as genetic mutations in a cell's transformation to cancer. ${ }^{2,3}$ Mechanisms of epigenetic silencing of tumor suppressor genes and activation of oncogenes include mostly unfamiliar names, such as alteration in methylation patterns, histone modifications, and dysregulation of DNA binding proteins. These epigenetic processes become more important as more and more research is carried out.

Of note, the epigenetic proteins that can alter and regulate gene function make up the epigenome. The epigenome is a network of chemical compounds surrounding DNA that modifies the genome without altering the DNA sequences and has a role in determining which genes are active in a particular cell. The epigenome initiates active genes and ultimately determines which proteins are produced in a particular cell. Conversely, the epigenome can suppress gene function and lead to cell death. Ultimately, understanding epigenetic mechanisms holds great promise for cancer prevention, detection, and therapy.

The article by Hsu and coauthors describes an additional wrinkle in the epigenetic process dealing with the mammalian target of rapamycin (mTOR) pathway. Most gene and gene products have names that make no sense. An "evil genius" seems responsible for assigning names to genes or gene products, and mTOR is no exception. mTOR is a name given to a member of the family of TOR proteins that are amazingly conserved across all living species. The evolutionarily conserved protein kinase, target of rapamycin (TOR), is a major effector of cell growth and proliferation by way of the regulation of protein synthesis. Since the discovery of TOR proteins in the mid-1990s, ${ }^{4}$ extensive research shows that mTOR controls protein synthesis through a stunning number of downstream targets. Some of the targets are phosphorylated directly by TOR, but many are phosphorylated indirectly but with TOR involvement.

In 1975, Vezina and colleagues ${ }^{5}$ isolated a natural product with antifungal and immunosuppressive properties from a strain of Streptomyces found in a soil sample collected on Easter Island. The natural product drug was named "rapamycin" for Rapa Nui, the native name for the island. ${ }^{5}$ Continued studies revealed the key role of rapamycin in limiting cell proliferation, but with new knowledge often comes complexity. Alternate pathways that are insensitive to rapamycin became apparent. Figure 1 outlines this complexity. Most thoracic surgeons will doze off when they see this illustration, and the only 


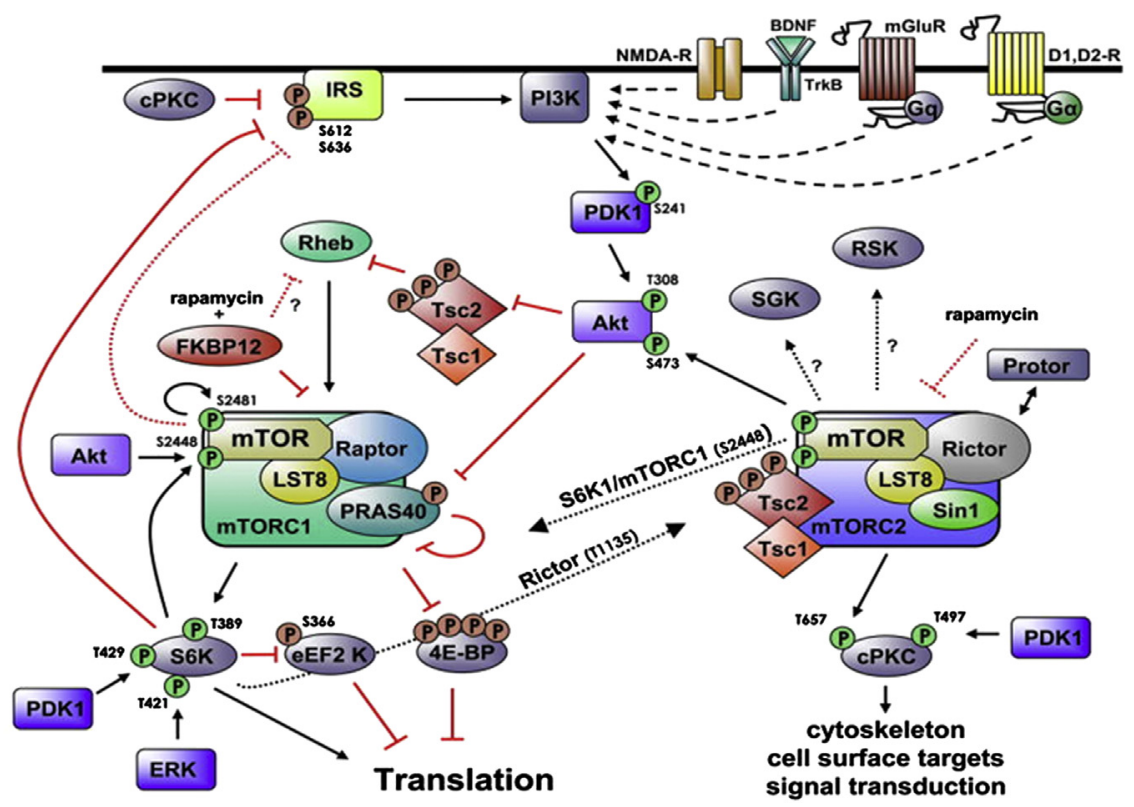

FIGURE 1. Epigenetic pathways of mammalian target of rapamycin (mTOR) that affect cell growth, proliferation, and transcription.

reason for including it is to give the reader a firsthand look at how our understanding of tumorigenesis is evolving.

Developing new approaches to targeting mTOR for cancer therapy requires more detailed knowledge of signaling downstream of mTOR. Such advances are likely to come from further work to understand the regulation of mTOR targets, such as components of the translational apparatus. The article by Hsu and coauthors is a step in this direction. They assessed the molecular pathways that may affect esophageal squamous cell carcinoma (ESCC) by evaluating the rapamycin-sensitive molecular pathway using in vitro cell cultures of genetically modified human ESCC. They evaluated one of the atypical protein kinase pathways (phosphatidylinositol $3^{\prime}$ kinase-related kinases) that is sensitive to rapamycin (mTOR). They studied the effect of rapamycin, an inhibitor of one part of the mTOR pathway, by looking at downstream proteins 4E-BP1 and eIF4E, both of which play a part in gene transcription and cell proliferation. The authors found that the balance of these 2 downstream proteins affects the ability of ESCC to proliferate in cell culture and the ability of rapamycin to limit cell proliferation.

This article by Hsu and colleagues gives the reader some inclination of the complexity of molecular pathways involved in tumorigenesis of esophageal cancer. Ultimately, molecular understanding of the epigenetic influence on ESCC tumorigenesis and offers a chance of novel treatments of this rather dismal disease. The authors do a commendable job of exposing the reader to the molecular pathways in the introduction, but I know, through a prolonged late-night journey through the Internet, that the authors are just skimming the surface of a complex process.

The authors found that epigenetic factors (histone deacetylase inhibitor and the DNA methyltransferase inhibitors), transcription factors (early growth response-1), and oncogene protein products (cyclin D1 and MDM2) either alter or are affected by the 4E-BP1/e1F4E protein ratio. Their experiments serve to reinforce the authors' premise that the $4 \mathrm{E}-\mathrm{BP} 1 / \mathrm{e} 1 \mathrm{~F} 4 \mathrm{E}$ ratio is key in the response of ESCC to rapamycin and possibly to newer cancer drugs. Further, the authors add new information to the burgeoning knowledge base of epigenetics.

This year, Adrian Bird, Howard Cedar, and Aharon Razin were front-runners to win the Nobel Prize for Medicine for their pioneering work in the field of epigenetics. They did not win, but their nomination must be a precursor of things to come. I believe in the importance of epigenetics and realize the complexity that exists. I suggest that future science prizes, including the Nobel Prize, will recognize the field of epigenetics. I cannot wait to see how this knowledge explosion will benefit our patients.

\section{References}

1. Hsu H-S, Lin M-H, Jang Y-H, Kuo T-T, Liu C, Cheng T-H. The 4E-BP1/eIF4E ratio is a determinant for rapamycin response in esophageal cancer cells. J Thorac Cardiovasc Surg. 2015;149:378-85.

2. Egger G, Liang G, Aparicio A, Jones PA. Epigenetics in human disease and prospects for epigenetic therapy. Nature. 2004;429:457-63.

3. Novak K. Epigenetics changes in cancer cells. MedGenMed. 2004;6:17.

4. Heitman J, Movva NR, Hall MN. Targets for cell cycle arrest by the immunosup pressant rapamycin in yeast. Science. 1991;253:905-9.

5. Vezina C, Kudelski A, Sehgal SN. Rapamycin (AY-22,989), a new antifungal antibiotic. I. Taxonomy of the producing streptomycete and isolation of the active principle. J Antibiot (Tokyo). 1975;28:721-6. 